\title{
Conference Proceeding for the 6th Annual Action Global Health Network Conference: A Student-led Movement Encouraging Advocacy, Research and Outreach
}

Ashley Marie Clare Cerqueira ${ }^{1}$, Andréanne Chaumont $^{1}$, Jennifer D'Cruz ${ }^{1}$, Melissa Govindaraju ${ }^{1}$, Syeda Shanza Hashmi ${ }^{1}$, Joanne Joseph ${ }^{1}$, Itai Malkin ${ }^{1}$

${ }^{1}$ Faculty of Medicine, University of Ottawa

All authors contributed equally.

ABSTRACT

On September 30th, 2017, medical students from the University of Ottawa organized and attended the 6th annual Action Global Health Network Conference (AGHN), in collaboration with the Faculty of Medicine. This full-day event aimed to challenge perceptions about global health and development, and encouraged participants to explore global health and social medicine as an avenue to improve equity. This conference proceeding recounts the key components of the 6th annual AGHN Conference, including keynote speakers, workshop speakers, and the research symposium. Core themes, learning takeaways, and future planning are also discussed in hopes of inspiring similar student-led initiatives across campuses.

\section{RÉSUMÉ}

Le 30 septembre 2017, des étudiants en médecine de l'Université d'Ottawa ont organisé et participé à la 6e conférence annuelle du Réseau Action Global Health (AGHN), en collaboration avec la Faculté de Médecine. Cet événement visait à remettre en question les perceptions de la santé mondiale et du développement et encourageait les participants à explorer la santé mondiale et la médecine sociale comme moyen d'améliorer l'équité. Cette conférence retrace les principaux éléments de la 6e Conférence annuelle AGHN, y compris les orateurs principaux, les conférenciers et le symposium de recherche. Les thèmes principaux, les enseignements tirés et la planification future sont également abordés dans l'espoir d'inspirer des initiatives similaires menées par des étudiants sur tous les campus.

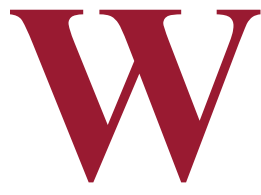

hile variations in its definitions exist, global health most commonly refers to the practice of working towards equitable access of health care and health promotive services in all countries and for all peoples (1-3). As a synergistic blend of international and public health, increased interest in global health has demanded shifts in public policy, provoked thoughtful research, increased focused philanthropic efforts, and is reflected in many educational sectors $(4,5)$. Current inclusion of global health material in Canadian medical curricula is limited due to a variety of factors, leading to the creation of student-led initiatives and learning opportunities discussing global health and its challenges (6-8).

At the University of Ottawa Faculty of Medicine, the global health curriculum is delivered through several mandatory lectures and service learning projects that allow students to engage with regional, national, or international organizations that support refugees, immigrants, and additional underserved populations. Additional learning is available through the newly implemented and faculty-supported Global Health Stream certificate program, international and global health clinical or research electives, and extracurricular activities and events. Furthermore, University of Ottawa medical students also utilize their passion for human rights advocacy and awareness by investing time into student-led initiatives that further their global health understanding. These events include fundraisers, interest groups, and advocacy campaigns, among others.

The largest and most attended of these student-led advocacy events is the annual Action Global Health Network Conference (AGHN Conference). The most recent iteration, the 6th annual AGHN Conference, was held on September 30th, 2017 and was organized by uOttawa medical students in collaboration with the Faculty of Medicine and supportive faculty members. This full-day multidisciplinary event included three inspiring and thought-provoking keynote speakers, 13 interactive workshops, and opportunities to network and learn from other participants. Additionally, the conference featured an original research symposium, which highlighted innovative global health research

Keywords: Global Health; Maternal Health; Human Trafficking; Health Promotion; Infant Health 
activities from across Canada. The events brought together students and professionals from a variety of educational backgrounds and provided a useful forum for networking, information sharing, improving global health awareness, and planning future advocacy initiatives. As future physicians, collaborating on such events not only improves communication and collaboration skills, but also assists future physicians with becoming leaders that are competent and thoughtful in their ability to understand gaps in health equity. Here, we discuss the success of the most recent conference as a framework for continued advocacy and action.

\section{KEYNOTE SPEAKERS}

The 6th annual AGHN Conference commenced with an excellent keynote speech by Dr. Zulfiqar Bhutta who is the Inaugural Robert Harding Chair in Global Child Health at The Hospital for Sick Children (SickKids), Co-Director of the SickKids Centre for Global Child Health, and the Founding Director of the Centre of Excellence in Women and Child Health at the Aga Khan University. In his presentation titled "Global Child Health: Challenges \& Opportunities," Dr. Bhutta discussed the current trends and progress in global child survival. He also helped our audience understand the key determinants of child survival and limitations of the Millennium Development Goals (9). He concluded by discussing key opportunities for accelerating progress in child health and related sustainable development goals - all of which were thoroughly insightful.

Our second keynote speaker for the day was Dr. Raywat Deonandan, who is an Epidemiologist and Science Communicator, specializing in global health. His research involves the creative analysis of administrative data; the epidemiology and ethics of assisted reproductive technologies, most prominently the emerging global industry of "reproductive tourism"; and the exploration of novel avenues of medical education. He gave us an overview of ethics in global health to help address fundamental topics including: the evaluation of key indicators of change to determine if markers of health are getting better or worse in global health, analysis of demographic transitions over the past decade to establish if the world is truly overpopulated, strengths and weaknesses of the sustainable development goals, poverty measures, and his own impression of the future of global health as a topic of study.

Our conference concluded with a fascinating keynote address by Dr. Nicole Rouvinez-Bouali who is a clinical investigator at the Children's Hospital of Eastern Ontario (CHEO) Research Institute and at the Ottawa Hospital Research Institute, as well as an academic neonatologist in the Neonatal Intensive Care Units at both the CHEO and The Ottawa Hospital - General Campus. She is involved in clinical research and quality improvement projects with the Canadian Neonatal Network. Dr. Rouvinez-Bouali's research interests include medical education, simulation, and reducing international infant mortality rates. She presented an intriguing and fascinating presentation titled, "In the skin of a 'worldly' neonatologist apprentice - How management principle can guide your journey in global health". She discussed her own experience navigating the global health arena by sharing general management principles for applying to international collaboration initiatives, including how to gain credibility in the context of global health. Dr. Rouvinez-Bouali further reflected on the existing resistance to change and the innovation paradigm in global health, and she concluded by highlighting the key elements to consider for long-term sustainability.

\section{WORKSHOP SPEAKERS}

Workshop sessions were organized into three streams, each highlighting a specific theme of global health. Attendees were presented with a series of relevant cases and engaged in thoughtful problem-based dialogue with expert speakers.

The first workshop series focused on "Pediatric Global Health", which included a variety of workshops that highlighted the barriers to promoting child health including displacement and poverty. Dr. Tobey Audcent led the Pediatric Refugee Health workshop, which explored the current global migration crisis with a focus on Syrian migration and its influence on child health. This workshop emphasized that displacement and war adds complexity to diagnosing even common pediatric diseases; and overcoming these barriers requires optimal access to healthcare services. Dr. Radha Jetty led the Inuit Child Health workshop, which explored the vitality of delivering culturally safe health care, through the narration of historical and current trauma impacting the Inuit communities. This workshop stressed that healthcare providers should be mindful of the multiple social determinants of health including poverty, food insecurity, and poor access to health resources when delivering health care to vulnerable populations like Inuit children. Dr. Heather MacDonnell led the International Child Adoption workshop, which focused on the rules, regulations, and methods of achieving international adoption worldwide. This workshop outlined the unique medical and emotional needs 
of children adopted internationally due to factors such as institutionalization and abandonment. Finally, Dr. Laura Muldoon led the workshop on Child Literacy, which elaborated on child literacy as an important tool in promoting child health both in Canada and in the global context.

The second workshop series focused on "Outreach and Empowerment". This session included a variety of workshops that highlighted the outstanding medical outreach and enrichment projects undertaken by the various speakers. Dr. Charles Adamson led the Medical Outreach in Guyana session, where he spoke of his experiences in Guyana and emphasized the positive impact and necessity of both medical and educational outreach projects in this geographic location. Dr. Ronald Labonte led the Globalization and Health Equity workshop, which underlined contemporary globalization as a determinant of health. This workshop outlined progressive taxation, international taxation, social protection and establishment of sustainable development goals as steps required to advance global health equity. Dr. McCarthy led the Infectious Disease workshop, which outlined the epidemiology, diagnosis, treatment, and prognosis of a variety of tropical diseases. Ms. Danielle Prapavessis led the Seed by Seed - Youth Obesity and Empowerment workshop which highlighted the use of youth empowerment as a bottomup approach to addressing youth obesity based on research conducted in New-Zealand with Pasifika youth. This workshop portrayed the positive outcomes of empowering youth to develop their own leadership skills through self-motivation, using film and social media as a platform.

The third workshop series focused on "Women's Health and Sexual Health". This session highlighted the challenges and barriers faced by women globally due to poverty, exploitation, and decreased access to proper maternal care. Dr. Laurence Bernard led the Global Women's Health workshop, which shed light on the current main causes of female mortality and morbidity in low- and middle-income countries including maternal mortality, obstetric fistulas, and cervical cancer. This workshop highlighted ministerial policymaking as an essential step to promoting change. Dr. Priya Gaba and Dr. Annelise Miller led the Maternal Health and Obstetric Outreach workshop, which highlighted the barriers and challenges faced by women during pregnancy because of poverty. This workshop emphasized the positive impact of outreach clinics in improving delivery of care to these women by increasing access to prenatal care and safe labour. Ms. Melissa Garcia led the Emergency Contracep- tion workshop, which provided an overview about the vitality of improving access to emergency contraception globally in addition to family planning and post-rape care. This workshop outlined the safety, indications, and the changing global trends of emergency contraception use. Mr. Steve Hudson led the Human Trafficking workshop, which focused on equipping healthcare professionals with tools to identifying and treating individuals victimized by sex trade. This workshop outlined the behavioural indicators of victims such as withdrawal and dependency, as well as the process of referring to social services including crisis workers and temporary shelters.

\section{RESEARCH SYMPOSIUM}

The AGHN Conference was delighted to see the outstanding level and the wide global breadth of the scholarly work presented. Following a competitive abstract application process, students from five universities across Canada presented original research focusing on one of five core Global Health themes: Women and Neonatal Health, Infectious Disease, Global Medical Services, Diversity and Barriers in Global Health and Systemic Issues.

Poster presenters were able to exhibit their work throughout the entire day. Therefore, conference attendees had the opportunity to discuss with the presenters during all scheduled breaks. We believe this offered a sufficient amount of time for both attendees and presenters to learn about international global health research. Awards for Best Presenter, Best Poster, and, Most Innovative Project with respect to global health research were selected based on votes from the conference attendees. The presented posters' conclusions and their respective Global Health theme can be found in Table 1.

\section{CONCLUSION}

The world is continuously becoming more interconnected. As such, it is no surprise that health issues increasingly transcend communities, provinces, and national borders. This year's Action Global Health Network conference aimed to stimulate conversation on local and international global health issues and helped forge new relationships among professionals from a variety of disciplines. Attendees had the opportunity to engage with experts in pediatric health, health outreach, women's health, and ethics. Moving forward, future iterations of the conference will continue to facilitate an environment where individuals passionate about global health can learn, network, and be inspired to become future catalysts for change. 
Table 1. List of research conclusions from poster presentations based on core global health themes.

\begin{tabular}{|c|c|}
\hline $\begin{array}{c}\text { Research } \\
\text { Symposium } \\
\text { Categories }\end{array}$ & Poster Presenters \& Research Conclusions \\
\hline $\begin{array}{c}\text { Women and } \\
\text { Neonatal } \\
\text { Health }\end{array}$ & $\begin{array}{l}\text { 1. Dieula Cazeau [Assessing the availability of abortion services in Quebec hospitals: A } \\
\text { mystery client study] } \\
\text { Hospital-based abortion in Quebec has remained steady over the last decade, as } \\
\text { Quebec hospitals approach the abortion process from social-psychological framework and } \\
\text { integrate social workers. This research also provides a baseline by which to assess the } \\
\text { incorporation of mifepristone/misoprostol into Quebec hospitals. } \\
\text { 2. Elyse Fortier [Exploring "Rapid Repeat Pregnancy" in Adolescent Mothers Living in Ottawa, } \\
\text { Canada] } \\
\text { There is a need to identify and further develop youth-friendly services that young } \\
\text { mothers feel comfortable accessing. Supporting efforts to increase adolescent mothers' and } \\
\text { service providers' awareness of existing services appears warranted. }\end{array}$ \\
\hline $\begin{array}{l}\text { Infectious } \\
\text { Disease }\end{array}$ & $\begin{array}{l}\text { 1. Ashley M. Cerqueira [Continuing Surveillance of Haemophilus influenzae in Northwestern } \\
\text { Ontario and the emergence of serotype a (Hla) as a significant cause of invasive disease] } \\
\text { Our results stress the importance of continued surveillance of } H \text {. influenzae in the post } \\
\text { Hib-vaccine era, and further supports the significance of developing a Hia vaccine to prevent } \\
\text { severe invasive disease. } \\
\text { 2. Jonathan Dench [When } 1+1 /=2 \text { : When a single canonical resistance determining loci } \\
\text { confers no resistance] } \\
\text { Using a novel in house computational method, we have identified numerous pairs of } \\
\text { correlated mutations from the whole coding genome of Pseudomonas aeruginosa. We found } \\
\text { that alone, the parC mutation confers no resistance to ciprofloxacin yet has strong positive } \\
\text { epistatic interaction with the gyrA mutation. } \\
\text { 3. Andreea Slatculescu [The spatial distribution of Lyme disease and infected ticks in the city of } \\
\text { Ottawa] } \\
\text { This study provides an update on the emergence of LD in the City of Ottawa based on } \\
\text { a fine scale spatial analysis of LD cases and infected ticks. It may help inform public health } \\
\text { officials and healthcare practitioners of the current risk of infection in the Ottawa region. } \\
\text { 4. Shabana Jamani [Can lice be transmitted by bathing in the river?: A study of prevalence and } \\
\text { beliefs in rural Honduras] } \\
\text { Children struggled with identifying modes of transmission and reservoirs. These gaps in } \\
\text { knowledge can also have severe consequences on the prevalence of head lice among children } \\
\text { With a lack of knowledge capacity being built and transferred in a school setting, it is } \\
\text { unsurprising that a stigma surrounding pediculosis capitis infestations is still perpetuated in La } \\
\text { Hicaca. }\end{array}$ \\
\hline $\begin{array}{l}\text { Global } \\
\text { Medical } \\
\text { Services }\end{array}$ & $\begin{array}{l}\text { 1. Dalia Karol, Itai Malkin \& Shirley Shuster [Save a Child's Heart - A leading model for global } \\
\text { health development] } \\
\text { Future global health initiatives should adopt the long-term sustainability model that } \\
\text { SACH and the Israeli team apply: } 1 \text { ) Use of a leading tertiary care centre; } 2 \text { ) International } \\
\text { screening missions with reliable NGOs; } 3 \text { ) Training local health care professionals at the } \\
\text { tertiary centre, and establishing care facilities in partner countries; } 4 \text { ) Volunteers perpetuating } \\
\text { the cycle by providing service, learning humanitarian work, and acting as local ambassadors. }\end{array}$ \\
\hline
\end{tabular}




\begin{tabular}{|c|c|}
\hline & $\begin{array}{l}\text { 2. Julia Boucher \& Meryl Hodge [SOARing to Morocco: A Sustainability Analysis of a New } \\
\text { International Elective] } \\
\text { This international elective is sustainable and culturally appropriate and should } \\
\text { therefore continue to be pursued in the future by medical students. } \\
\text { 3. Ashley M. Cerqueira [The Utility of Photovoice Journaling in teaching Critical Reflection Skills } \\
\text { following Global Health Post-Electives in Canadian Undergraduate Medical Education] } \\
\text { Our project reinforces the significance teaching reflection in medical education, the } \\
\text { importance of post-GHE debriefing, and the value of creative Photovoice platforms. }\end{array}$ \\
\hline $\begin{array}{c}\text { Barriers in } \\
\text { Global Health } \\
\text { and Systemic } \\
\text { Issues }\end{array}$ & 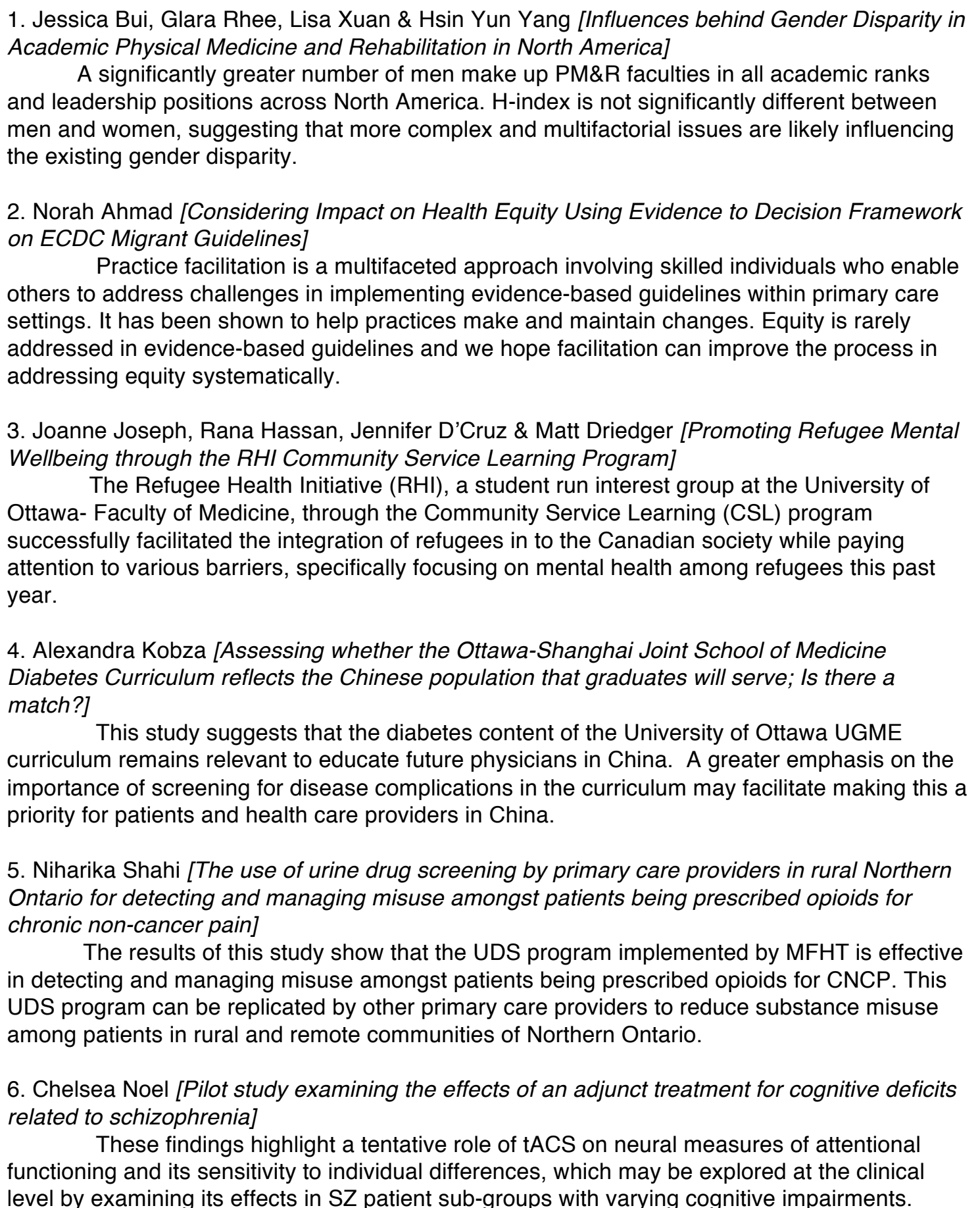 \\
\hline
\end{tabular}




\section{ACKNOWLEDGEMENTS}

We would like to thank this year's planning committee for their hard work and dedication to creating this event, including Ashley Cerqueira, Jennifer D'Cruz, Melissa Neethu Govindaraju, Adam Suleman, Alexander Pearson, Itai Malkin, Andréanne Chaumont, Danusha Vinoraj, Fabiha Rahman, Frank Battaglia, Glara Rhee, Jasjit Singh, Joanne Joseph, Olivia Cheng-Boivin, Ruby Yang, Shanza Hashmi, Sheridan Parker, and Yipeng Ge. We would also like to thank the University of Ottawa's Faculty of Medicine and the Department of Family Medicine for conference funding, as well as Dr. Anne E. McCarthy and Desiree McCaughey-Miller of the Global Health Office for their invaluable financial and logistical assistance in executing the AGHN Conference. Finally, we wish to extend a large gratitude to the 23 students who presented their scholarly work, the 18 workshop leaders and the 3 keynote speakers who work to inspire the next generation of social advocates and leaders.

\section{REFERENCES}

1. Beaglehole R, Bonita R. What is global health? Glob Health Action. 2010 Apr;3: 10.3402/gha.v3i0.5142.

2. Koplan JP, Bond TC, Merson MH, Reddy KS, Rodriguez MC, Sewankambo NK, Wasserheit JN. Towards a common definition of global health. Lancet. 2009 Jun;373:1993-1995.

3. Sebert Kuhlmann A, lannotti S. Resurrecting "international" and "public" in global health: has the pendulum swung too far? Am J Public Health. 2014 Apr;104(4):583-585.

4. Cooper BA, MacMillan BD, Beck RA, Paterson ML. Facilitating and evaluating a student-led seminar series on global health issues as an opportunity for interprofessional learning for health science students. Learning in health and social care. 2009 Feb;8(3):210-222.

5. Opollo JG, Bond ML, Gray J, Lail-Davis VJ. Meeting tomorrow's health care needs through local and global involvement. Journal of Continuing Education in Nursing, J Contin Educ Nurs. 2012 Feb;43(2):75-80.

6. Drain PK, Primack A, Hunt DD, Fawzi WW, Holmes KK, Gardner P. Global Health in Medical Education: A Call for More Training and Opportunities. Academic Medicine. 2007 Mar;82(3):226-230.

7. Houpt ER, Pearson RD, Hall TL. Three Domains of Competency in Global Health Education: Recommendations for All Medical Students. Academic Medicine. 2007 Mar; 82(3):222-225.

8. Izadnegahdar R, Correia S, Ohata B, Kittler A, ter Kuile S, Vaillancourt, S, Saba N, Brewer TF. Global Health in Canadian Medical Education: Current Practices and Opportunities. Academic Medicine. 2008 Feb;83(2):192-198.

9. World Health Organization. Health in 2015: from MDGs, Millennium Development Goals to SDGs, Sustainable Development Goals. Who Press; 2015. $216 p$. 